\title{
Application of Project Teaching Method in Automobile Engineering Drawing
}

\author{
Mao Yin \\ School of Mechanical Engineering Dalian Vocational \& Technical College, Dalian, China. \\ mydxyx_2011@163.com
}

\begin{abstract}
Keywords: Project teaching method; Automobile engineering drawing; Vocational education
\end{abstract}
\begin{abstract}
. the project teaching method is a new attempt in the course of automobile engineering drawing. On the basis of problems in the traditional teaching process and characteristics of the project teaching method, this paper attempts to apply the project teaching method to automobile engineering drawing course, re-examining the role of teachers in the teaching process, giving full play to students' autonomous learning, and thus achieves the purpose of improving the teaching effect. Finally, the education philosophy of "learning to do, in the middle school" is implemented.
\end{abstract}

\section{Introduction}

"Automotive Engineering Drawing" is an applied professional foundation course with rigorous theory and strong practicality, and also is the first course for engineering training students. The mastery of this course will directly affect the learning of following courses and professional skills. From the perspective of teaching practice, the teaching contents and methods of the traditional teaching, the students feel that learning is difficult and that the enthusiasm for learning is difficult to stimulate, and that the teaching and learning interaction is poor. All of this go against the cultivation of students' engineering quality and engineering application ability [1]. To solve these issues, we have carried out the reform of the course. In view of this situation, based on the project driven method to the automobile engineering drawing curriculum reform, the practice proves that this method has good teaching effect.

\section{Project Teaching Method}

Project teaching method originated in the United States and was prevalent in Germany. It is oriented by the work process, ability standard, students as the main body, and is teaching activities through the implementation of a complete project. The project teaching method integrates the curricular system of the traditional knowledge, skills and occupation accomplishment fusion into several course project, constructing project oriented learning unit vector, teaching around the project and organization, breaking the traditional "classroom centered, teacher centered and textbook centered" teaching mode and allowing the students to participate in the whole process of exploring creative potential, cultivating ability, innovation ability, method to solve the problem of accepting new knowledge learning ability and cooperation with people and projects of social ability [2].

\section{The Necessity of Implementing the Project Teaching Method}

As everyone knows, Automotive engineering drawing is a bias of practical curriculum, and curriculum content is mostly related to site operation. Too much theoretical knowledge not only reduces the ability of students' practical thinking, but also to some extent hinders the students' thinking, which results in that the students cannot use the knowledge when meeting the practical problem. Therefore, students learns passively with lower interest, so it is difficult to grasp the basic knowledge. Once applied in practice, there will be the phenomenon of knowledge theory cannot be linked to the actual phenomenon. Practical application is a fundamental goal in the project teaching method as well as the student as the main body and the teacher as the leading factor, at the same time, the method focuses on specific projects through the construction of teaching content system, 
while both teachers and students participate in the completion of a personal project. In the implementation process of project driven method in, the appropriate assistance in the completion of the project in the process enable students to master the basic content of the curriculum according to the needs of students learning, personal practice, and timely guidance of teachers. Obviously, this kind of teaching method makes students from passive learning to active learning and mobilizes the enthusiasm of the students, and truly reflects the educator Mr. Tao advocated "do in learning, learning by doing" philosophy of education [3].

\section{The Characteristics of the Project Teaching Method}

Stimulating the Enthusiasm of Learning and Mobilizing the Subjective Initiative. In the process of project implementation in practice, students need to grasp knowledge and skills and understand the curriculum requirements and the requirements of the project, then experience the fun and hardships in the study of innovation in the project, in order to cultivate the comprehensive quality and the ability to analyze problems and to solve the problem by themselves. Moreover, students can exercise the complete manufacturing process and manufacturing process from the process of mechanical drawing, mechanical parts design drawing-check, and then change the traditional teaching procedure: teacher explains teacher, demonstrates main point and emphasizes students practices. At the same time, the students can feel the learnt knowledge in the classroom, the scientific skills and personal growth in the future occupation through the study of the project, which can stimulate students' learning enthusiasm and interest in learning [4]. In the implementation of project teaching process, the teacher should try to lead the students to study the practice in the interested project to develop the occupation skills and practice ability.

Cultivating Students' ability, Cooperation, and Innovative Spirit. On the teaching process to organize the implementation of the project teaching method is characterized by the form of group, this is not only for students' practice, thinking, analysis, solving and innovation ability of the training, but also for the students' teamwork exercises.

Integration of theory and Practice. Project teaching method is to realize the integration of students and teachers' practice. The project teaching method in accordance with the requirements of the professional teaching environment, equipped with the necessary equipment, layout of maps, tools and teaching model. This will change the traditional teaching methods, so that students can learn in the professional classroom and training room to promote the ability of students in practicing the theory.

\section{The Implementation Process of Project Teaching Method}

The basic framework of project teaching model includes five teaching stages: (1) student groups, assigning tasks,(2) the group analysis, planning, division of labor, (3) the implementation of the project , (4) project acceptance, examination and evaluation, (5) the project archive. In this paper, I take the gear oil pump as an example in this course to introduce the specific implementation steps of project teaching method:

Grouping of Students and Task Assignment. The teacher prepared a number of gear pump and disassembly tool, tried to make the structure of the same batch of gear pump similar difficult, then guided students to set up the project team. The number of each group was decided by the total amount of the project, generally, each group has 3-5 students. The grouping is based on the principle of complementarity, which is excellent, poor students, boys and girls as a group, so that we can learn from each other and improve each other, each group chooses a leader to assist the work of teachers [5]. The teachers were randomly selected from a gear pump, gear pump models of each group according to determine the name of project: XX type reducer parts of Surveying and mapping, and develop project tasks: each student draws a complete standard assembly drawing of gear pump and 3-4sheets of non-standard parts drawing. Finally, a set of best and complete expression of the gear oil pump working plan should be selected from all the drawings.

Analysis in Group and Making Plan. The leader of each group organize all members to 
carefully discuss the projects teachers assigned with the help of the teachers' task provided in the book, as well as through access to information, for teachers and other ways to completely clear the task to determine the working principle of gear pump, and the gear pump includes the following four sub projects: gear pump gear box mapping, surveying and mapping, surveying and mapping, the gear pump cover shaft mapping. Each of the sub project is included in the following aspects: Surveying and mapping parts preparatory work, drawing sketch and dimensioning and technical requirements, determine the parts drawing, each project group according to the project content, formulate the project implementation schedule and the implementation of the project schedule, and discuss the determination of team members of the Division of labor, to organize their own learning related knowledge. Each team member can have a whole understanding of the project to be completed and understand what to do. The project team will be carried out on a regular basis to report to the teacher, in a timely manner to absorb the opinions and suggestions made by the teacher [6]. Finally, teachers should give the project team issued project instructions, instructions including how to choose the scheme expression parts, how to use various measurement tools, selection of labeling requirements and technical dimensions, drawing the part and assembly drawing sketch notes and so on.

The Division of Labor, the Implementation of the Project. Each project team complete the drawing of all parts of the gear oil pump sketches and marking dimensions according to their own implementation plan, the division of labor to. In the meantime, different groups can discuss and communicate between them and the teacher is responsible for the inspection, guidance and explanation. The teacher communicates with the team members and propose advice according to the sketch handed in. And take this opportunity to explain the common problems in the classroom and correct the error. Finally, the students complete the drawing of gear oil pump assembly and non-standard parts to meet the project requirements according to the advice.

The Acceptance, Inspection and Evaluation for the Project. Each group provide a complete drawing of gear pump assembly and relevant parts, teachers will submit the score sheets and drawings to those who have practical experience, and let them evaluate the results from the point of part machining, At the same time, teachers also distribute the score sheets to students, then let one member of a team tell and show the results of their projects and make evaluation. The indicator of Evaluation includes correctness of the program, reasonability of the dimension and the processing property. Finally, teachers determine the results of the project. Then, teachers summary the project, point out the problems, and then select the best the drawings for production, to deepen the students' sense of achievement.

Project Pigeonhole. The teacher will collect the personal work logs, work process, experience and suggestions project design report, project results, a series of material retained, and the good implementation methods and techniques in the process to provide reference for the same type project.

\section{Application of Project Teaching Method to Achieve the two Changes}

Change the Teacher as the Center to the Students as the Center. In the traditional teaching process, the process is mainly teacher centered, after teachers explain the knowledge, students complete the homework. The learning initiative, enthusiasm of the students is not high. But in the project teaching, the students become the main body of the teaching, the teacher in the teaching process guide the students, the students learning theory knowledge while completing the project tasks. The completion of a project task not only increased the enthusiasm of the students in learning, but also cultivate students' ability of autonomous learning. At the same time trained the ability of students in the learning process. The teacher as a supporting role, its core is no longer transferring ready-made knowledge and skills to students as the target, but teaching the students to find ways to get the results $n$ Learning focuses on the learning process, rather than the results of the study. Teachers should act as a guide, guide and supervisor.

Change Taking the Textbook as the Center to Taking the Project as the Center. Project Teaching takes the theoretical knowledge into specific and practical work process, students have 
more pertinence and practicability within a certain time. The teacher guides the students to use learning drawing knowledge and skills to complete related task. The teachers complete the e task of teaching during the process, the learning methods of students change from receptive learning to active, autonomous learning.

\section{Conclusion}

Project driven teaching method strengthens the initiative of students, so that students grasp more basic knowledge in-depth and solid, the students pay a lot, while the harvest is also great. The project driven method is used in the teaching of automobile engineering drawing, which is the inevitable trend of the development of the drawing course, and also the need of realizing the goal of training innovative talents. It requires teachers to update teaching concepts, to be familiar with professional practice, and to create teaching situation, and also requires students to have a strong self-learning ability, the ability to work with others, and the ability to work independently. Through solving practical problems, Project teaching method help students to master the knowledge and skills, and then greatly improves the enthusiasm and initiative of students learning. It makes the students' ability to work, the ability to solve problems and the overall quality of the students have a greater degree of improvement.

\section{References}

[1] Feng Dongju, Wang Danhong, $\mathrm{Xu} \mathrm{Xu}$, the teaching reform of mechanical drawing based on project driven [J] laboratory science 2016 (6): 25-27

[2] Dai Shihong. Teaching reform of vocational education curriculum. Beijing: Tsinghua University press, 2007:40

[3] Zhang Weisheng. Analysis of project teaching in the application of mechanical engineering [J] Henan science and technology 280 (1) 2014

[4] Guo Guo. The application of project teaching method in higher vocational skill courses [J] adult education, 2011 (06)

[5] Li Mei, Shuqi Tong, Zhang Xueli. Engineering drawing course teaching reform and exploration project [J]. Journal of Kunming College of Metallurgy, 2011,27 (1): 73-76

[6] Sun Weihan, the Edmonton. Based on Project Teaching "mechanical drawing" teaching material construction exploration [J]. Journal of Jiamusi Institute of education, 2011 (2): 128-129 